\title{
Multidisciplinary Higher Education Strategies in Small Groups of Health and Social Sciences
}

\author{
Luis-Lucio Lobato Rincón ${ }^{1}$, Ricardo Bernárdez Vilaboa ${ }^{1}$, Fernando Santander del Amoํㅣ Juan Carlos Cuevas \\ Lanchares $^{1}$, Maria Corres-Illera ${ }^{1}$, Mercedes López Suárez ${ }^{1} \&$ Josefina María Illera del Portal $^{1}$ \\ ${ }^{1}$ University Complutense of Madrid, Spain \\ Correspondence: Luis-Lucio Lobato Rincón, University Complutense of Madrid, Spain
}

Received: August 13, 2020

Accepted: October 3, 2020

Online Published: October 14, 2020

doi:10.5430/ijhe.v10n1p122

URL: https://doi.org/10.5430/ijhe.v10n1p122

\begin{abstract}
The Small Group Learning (SGL) permeates throughout higher education fields of study. Thus, our aim is to assess the influence of a planned activity of SGL on a variety of competences appraisals through a multidisciplinary perspective. To that end, cooperative learning activities implemented under the SGL approach were programmed for six different degrees. For each activity, students were provided with instructions about what the activity was about and how to make it. Two surveys were scheduled before and after the completion of the SGL. Our findings are presented in a descriptive and quantitative analysis, using surveys with which we examine the pre and post differences in students' self-reports. As a result, self-perceptions on oral and written expression and bibliography competence increased after the practice of the Small Group Learning (SGL) strategy in students from Social Science degrees as well as in students from Psychology degree. In addition, receiving feedback showed an improvement for the whole sample after doing SGL. Our results confirm that, in order to achieve an excellent quality education, SGL could be applied equally in different fields of study: both Health and Social Sciences. The novelty of this study is that it has been conducted in six different academic degrees and has focused on higher education skills in order to improve future undergraduate's employability.
\end{abstract}

Keywords: higher education, multidisciplinary, cooperative learning, Small Group Learning, competences

\section{Introduction}

The education paradigm has evolved from the master class, where students are passive subjects; to a collective cooperative learning, where students become active subjects of their own learning (Johnson et al., 1999). Most professors show a positive attitude towards this change in paradigm, although change is not always seen in a constructive way. The older the professor, the more difficulty he or she will have in comfortably handling a class where the use of new strategies or types of technology is demanded (Saborit et al., 2016).

More and more, higher education demands a practical, less theoretical formation, inclined to favor the chances of students to easily transition from university to the workforce. Therefore, this requires changing academic habits considerably that look inward (in the degree), such as incorporating professional lectures in post-graduate courses; instead of outward towards internships and other forms of hands-on experience.

Another clear change during the last decades of the $20^{\text {th }}$ century, has been the focus on competences in the educational context in general, particularly in the context of higher education. One of the first definitions of competences was proposed by McClelland, a Harvard professor from the 1970's, who considered that competences were the attitudes, knowledge and abilities that were needed to develop a given occupation (McClelland, 1973). Afterwards, each profession has specified its own list of required abilities, that can range from good communication skills to critical thinking (Epstein \& Hundert, 2002).

The abilities model in education has been oriented towards the transformations that knowledge society is experiencing, such as: the increase in the level of requirements, formation needs, and the permanent crisis of scientific-technical formative content. Thus, abilities such Oral and Written Expression, Analysis and Synthesis or Organizing Information, among others, are considered basic at an early school level of education (Lecce et al., 2017), and crucial in higher education (García-Aracil et al., 2004; Bergsmann et al., 2015; García-Aracil et al., 2014). Also, these types of abilities maintain a strong relationship with the occupational status of the future worker (Blázquez et al., 2018). The 
acquisition of emotional intelligence skills such as: teamwork, leadership, and the like; may lead to higher paying jobs resulting in a greater satisfaction with their work life. (García-Aracil et al., 2004).

Given the amount of competences evaluated, and their importance, it is also relevant to analyze the learning method that students use to learn, as well as the approach professors and lecturers propose when teaching. In fact, in the context of higher education, several strategies are proposed to develop competences such as: simulations in nursing school studies, for Health Science (Saaranen et al., 2015); learning based problem solving for Business Direction and Administration, in Social Sciences (Carriger, 2016); Small Group Learning (SGL) for Sciences, Mathematics, Engineering, and Technology (Springer et al., 1999).

Specifically, SGL has long been used as an educational technique. SGL is usually applied to groups of no more than eight students, with the optimal number of participants being six (Bonafé, 2004). The type of activities associated to this approach can include seminars, workshops, or projects. Furthermore, it has been demonstrated that in higher education, cooperative learning promotes meaningful relationships between the members of the group and increases the psychological wellbeing of its participants (Johnson \& Johnson, 2014). This is due to the fact that expressing opinions and working together, stimulates the sense of self-worth and makes the activity more pleasurable, resulting in a more effective learning exercise (Andreu-Andrés \& García-Casas, 2015).

SGL is based on cooperative learning principles which allow the achievement of individual and group goals. Making possible that one particular participant can only reach his or her goal if the whole group does so as well (Johnson et al., 1999). This type of learning has effects not only on the knowledge obtained (Springer et al., 1999) but also in motivation (Fernández-Rio et al., 2017), attitudes (Steinert, 2004) and humanitarian aspects such as citizen behavior, concern for others and views about diversity (Schul, 2011).

Several studies about basic science disciplines (Engineering, Mathematics and Other Sciences) have found that the inclusion of SGL improved the learning process (Deep et al., 2019; Johnson, 1999; Springer et al., 1999).As well as Health Sciences (Baghcheghi et al., 2011; Bahar-Özvaris et al, 2006; Khantan \& Mills, 2007); Social Sciences and Education (Herrman, 2013; Norman et al., 2004; Veenman et al., 2002).

Recent literature also concurs that promoting critical thinking and self-reflection are positive effects from the application of SGL to the learning process (Brindley et al., 2009). SGL promotes as well other non-cognitive effects for the self-esteem of the participants, and also an already demonstrated improvement of interpersonal relationships among people of different cultural backgrounds, nationalities, or disabilities (Slavin, 1983).

Therefore, this background gives strength to the idea that SGL is an important tool for innovative education in order to achieve both cognitive and non-cognitive effects. In fact, the type of outcome that will enable undergraduates to face a world that is becoming increasingly complex is not only theoretical knowledge, but also skills and abilities which are interrelated to competences.

The changes already underlined encompass new practices in teaching. Among those practices, SGL has given empirical evidence of its efficacy in many studies. We have chosen to study with SGL because it is one of the more misunderstood and underdeveloped techniques in the real context of the higher education. In addition, there are no studies that evidence the effect of SGL on a multidisciplinary level. Thus, this inquiry focuses on examining the impact of SGL in different disciplines of higher education from two scientific fields: Health and Social Sciences. This angle on the different fields of study is in line with Morin's hybridization (2011) in reference to the future of higher education and society itself.

Therefore, taking into account the gap in knowledge about the use of Small Group Learning in multidisciplinary degrees, and the call for boosting the communication between different disciplines, the objective of the present article is to demonstrate the influence of this educational tool on the appraisal of certain competences selected for this study and relevant for undergraduate's performance. In fact, the novelty of this study is that it has been conducted in six different degrees, of different Faculties at the Universidad Complutense de Madrid (UCM).

At the same time, four hypotheses have been proposed for testing. Our hypotheses are that SGL will improve student perceptions on oral and written expression, organization of information, managing the bibliography and analysis and synthesis, respectively.

\section{Methods}

\subsection{Approach}

We have chosen to apply SGL strategies to our inquiry because of the intrinsic characteristics that this form of learning has on the improvement of interpersonal development: active learning gives way to more opportunities for personal 
feedback. SGL also provides the instructor with an effective way to evaluate the students' acquisition of core competences and to know their perceptions and expectations.

The methodology applied in this research is descriptive and quantitative. With the use of surveys we have collected over 1.000 samples of data with more than 500 participants. Moreover, this study has brought together professors from all categories and fields of study that share a common goal: to better understand their student's learning process. Thus, the seven researchers of this inquiry vary from assistant to full professor across a diversity of study fields.

In order to attain the most accurate scientific data in accordance with our findings, a survey was designed and conducted twice during the school year at very specific times (pre-test in October and post-test in January). Firstly, this choice was to measure the appraisals about the capabilities with which students inherently came to our classes. Secondly, this design allowed us to assess the developed perceptions on competences during the school year.

\subsection{Context and Participants}

Our findings are based on a survey given to 583 students - $80 \%$ women, $20 \%$ men - ranging from ages 19 to 22 , from which the median age was 21.33 with a standard deviation of \pm 1.83 .

The participants were of a multidisciplinary variety. The study comprised six majors among different fields of study from the Universidad Complutense de Madrid (UCM). The majors selected were: Veterinary Medicine, Optometry and Vision Science, Psychology, Tourism, Political Science, and Sociology. The collection of data took place in the respective courses of the following subjects: Animal Physiology (Veterinary Medicine), Psychology of perception (Psychology), Optometry II (Optometry and Vision Sciences), Political Institutions and Power Structures (Both Political Sciences and Sociology) and Geography of Tourism (Tourism). This constitutes a unique opportunity to evaluate and test abilities in multidisciplinary fields of study.

\subsection{Process and Data Collection}

At the beginning of the semester, a pre-test survey was given to the small groups. Deciding to use Garfield's (1993) organization and sample both voluntary and formal groups, in order to achieve adherence to the strategy and to give the desired outcomes enough time to develop.

The content instruction was to collaborate together in a one-month project, which involved collecting, analyzing and interpreting data about a topic from the teaching plan. In order to facilitate the intrinsic motivation, the election of the topic was freely assigned by the proper group. Groups could meet in and/or outside the classroom, in order to work on these projects. Finally, they had to present their findings in an oral in-class presentation.

The procedure instruction for SGL was to emphasize the need to take a more active role by the members of the group, where asking and solving other's members doubts were behaviors highlighted as more adequate than a passive style. In addition, some role categories were suggested to all participants. Suggestions were made in order to organize group. Examples of those suggestions were the proposal of roles such as a "moderator", someone who coordinates the activity; a "checker", someone who synthesizes solutions; or a "recorder", someone who transcribes the most relevant communication exchanges.

The activity would be assessed by assigning the same grade for the all the members of the group.

On the other hand, the pre-test and post-test survey questions were designed to be applied equally in our range of multidisciplinary areas. There was a paper-and-pencil version of the survey, as well as an electronic one, using the Kahoot mobile application (www.kahoot.com).

The questionnaire had a total of 10 dichotomous questions with a yes or no answer proposed always in the same order. Each question had a short time response of 30 seconds controlled by the Kahoot app or by the examiner in the paper-and-pencil case.

Through those 10 questions, we assessed students' self-perceptions on 4 main competences:

A) Oral and Written Expression Competence:

Previous experience: Item A1. "Have you ever done an oral presentation in class -individually or in a group- that lasted more than 10 minutes?"

Feedback received: Item A2. "At this University, have you ever gotten feed-back for your work?"

Amendments after suggestions: Item A3. "Do you implement the changes suggested by your instructor?"

B) Organizing Information Competence:

Synthesizing: Item B1. "Can you synthesize a text in five lines capturing the two or three main ideas?" 
Previous activity to improve communication: Item B2. "Have you ever done any activity in small groups that has improved your communication skills?"

C) Bibliography Competence:

Databases knowledge: Item C1. "Do you know how to use data bases and collect a bibliography for a research paper in your specialty?"

Complementary information: Item C2. "Do you search for complementary information about a topic that interest you from a class or lecture (author, bibliography, etc.)?”

D) Analysis and Synthesis Competence:

Citing: Item D1. "Do you know the steps to take in order to extract and cite information from a text?"

Individual self-efficacy: Item D2. "Do you feel capable of writing a summary and presenting it in class?"

E) Additional Satisfaction Question:

"Do you feel comfortable by doing these group activities?"

The surveys took place in the student's usual academic space and time period. Therefore, students' participation in this exercise did not in any way negatively impact their normal behavior in their day-to-day university life. In fact, since the participation in this survey took less than 10 minutes, it did not even steer them away from their ordinary routine.

\subsection{Data Analysis}

We have used a quantitative method to analyze the results of our surveys. Thus, the analytics has been processed using SPSS statistical package (version 25) for descriptive and inferential statistics. In order to rule out the possible differences that could appear when dealing with different fields of study, we used the Chi-square test with a 95\% trustworthiness.

\section{Findings}

The object of this study has been to demonstrate the effect that SGL can have on higher education student's self-perception of four critical competences. Along these lines, we address both the descriptive and inferential analysis carried out in this research.

\subsection{Descriptive General Results}

We will begin by describing the amount of data registered in terms of percentages for options "Yes" (positive responses towards the given question) and "No" (negative responses towards the given question) during both phases (pre- and post-), bearing in mind that no "Yes" answer was below a 50\% frequency.

On the one hand, the lowest percentage for a "Yes" response was on the question about searching for complementary information (51.6\%) followed by the question about feedback to presentations done $(57.8 \%)$.

On the other hand, the highest percentage of "Yes" responses was obtained in three questions: previous experience, amendments after suggestions and synthesizing. These three examples offered above $80 \%$ of "Yes" responses.

\subsection{The Effect of SGL on Pre- and Post-Self-Perceptions on the Whole Tested Sample of Students}

Taking all of the tested students as a whole sample -without factoring in the degree or faculty to which they are ascribed to - we can conclude that the only significant improvement $(p=.02)$ is for item A2 "Receiving Feedback From Instructors About Their Work". Showing a 9.3\% increase in affirmative responses after the application of the SGL strategy.

\subsection{The Effect of SGL on Pre- and Post-Self-Perceptions in One or More Degrees}

Next, the most relevant results are presented associated to the specific educational degrees for each of the competences researched.

\subsubsection{Oral and Written Expression}

In regards to Item A1 - "Have you ever done an oral presentation in class -individually or in a group- that lasted more than 10 minutes?"; for the post questionnaire we obtained the highest increase in the number of affirmative responses in the Veterinary Medicine as well as in the Social Sciences degrees. The results are displayed in Figure 1. 


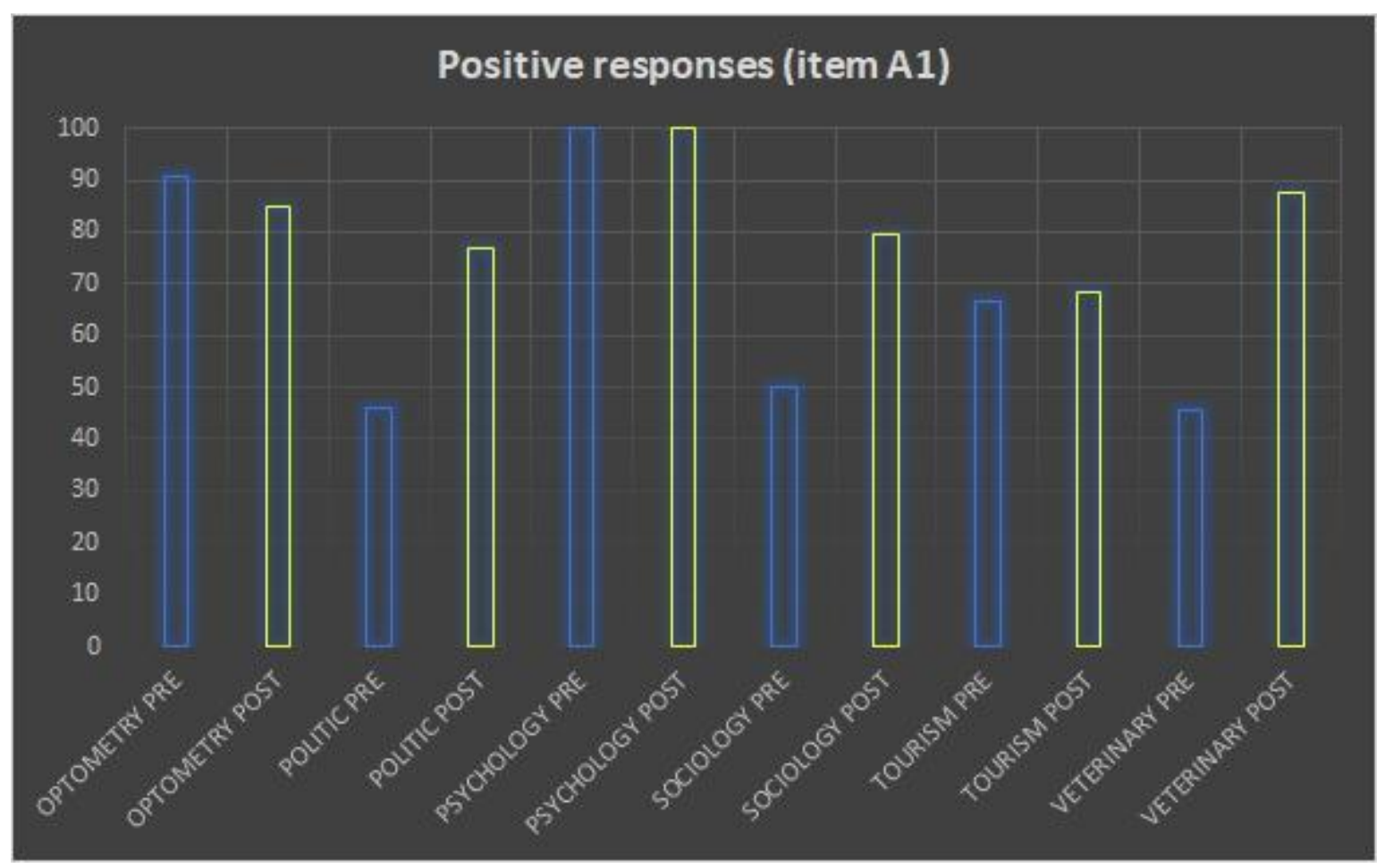

Figure 1. Percentage of positive responses on Pre and Post Tests in item A1 for all academic degrees: "Have You Ever Done an Oral Presentation in Class -Individually or in a Group- That Lasted More Than 10

Minutes?"

In the next table (Table 1) we can observe the majors and degrees with statistical significance regarding Item A1. Specifically, we found significant changes in the degrees of Political Sciences $(p=.005)$ and Sociology $(p=.02)$, respectively. In the case of Veterinary Science, self-perceptions about the past experience on presentations were only slightly non-significant $(p=.06)$. All the students from the Faculty of Psychology had experienced a previous presentation, so no change could be analyzed in this case.

Table 1. Chi-Square values and significant differences between Yes and No, in Pre and Post Tests in item A1" Previous experience on presentations longer than 10 minutes" for all academic degrees

\begin{tabular}{llll}
\hline Group according Degrees & Pearson Chi-Square Value & df & Signification asymptotic (bil.) \\
\hline OPTOMETRY & 2.530 & 1 & .112 \\
POLITICAL SCIENCE & 8.049 & 1 & $.005^{*}$ \\
PSYCHOLOGY & - & - & - \\
SOCIOLOGY & 5.412 & 1 & $.020^{*}$ \\
TOURISM & 0.019 & 1 & .891 \\
VETERINARY SCIENCE & 3.519 & 1 & .061 \\
\hline
\end{tabular}

* Statistical significance.

With respect to Item A2 - "At this university, have you ever got any feedback for your work?" the total number of affirmative responses was higher in the post survey for any group evaluated, as it can be seen in Figure 2. 


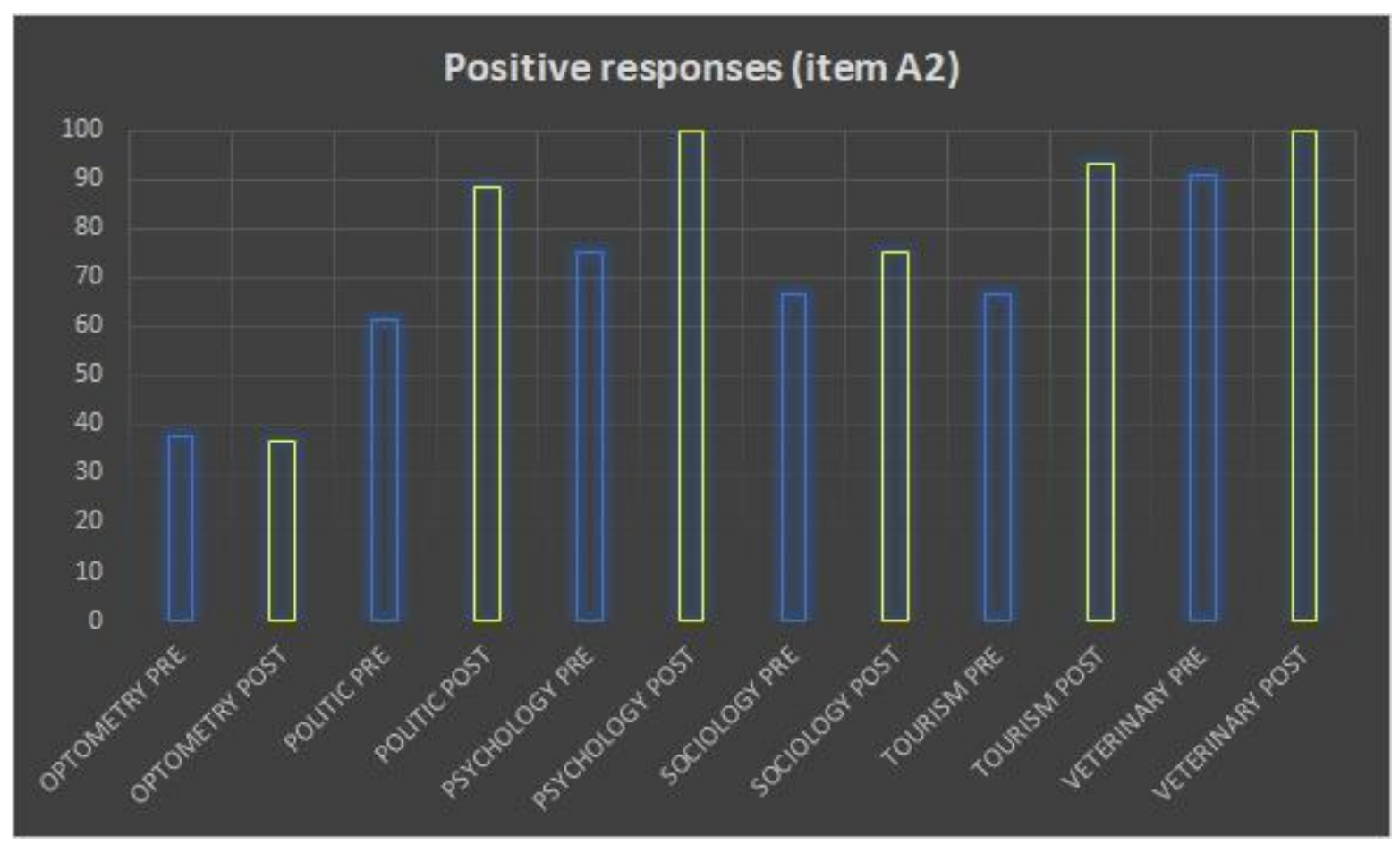

Figure 2. Percentage positives responses on Pre and Post Tests in item A2 for all academic degrees:" At this University, have you gotten feedback for your work?"

Furthermore, we found significant differences on pre- and post- self-perceptions for two degrees of Social Sciences in Item A2: Political Science $(p=.005)$, and Tourism $(p=.003)$. In addition, a mixed discipline as Psychology, which draws on both Health and Social Sciences, also showed significance $(p=.015)$. There is no other statistical significance for the rest of academic degrees, as can be observed in Table 2.

Table 2. Chi-Square values and significant differences between Yes and No, in Pre and Post Tests in item A2: "At this University, have you ever gotten feed-back for your work?" for all academic degrees

\begin{tabular}{llll}
\hline Group according Degrees & Pearson Chi-Square Value & df & Signification asymptotic (bil.) \\
\hline OPTOMETRY & 0.45 & 1 & .831 \\
POLITICAL SCIENCE & 7.985 & 1 & $.005^{*}$ \\
PSYCHOLOGY & 5.909 & 1 & $.015^{*}$ \\
SOCIOLOGY & 0.446 & 1 & .504 \\
TOURISM & 8.660 & 1 & $.003^{*}$ \\
VETERINARY SCIENCE & 0.768 & 1 & .381 \\
\hline
\end{tabular}

* Statistical significance.

Regarding Item A3 "amendments after suggestions", significant differences were only found in Political Science, which showed an increase of $15.8 \%$ in "yes" responses $(p=.01)$.

\subsubsection{Organizing Information Competence}

With regards to Item B1 - "can you synthesize a text in five lines capturing the two or three main ideas?" our sample did not present significant differences.

In what concerns Item B2 - "have you ever done any activity in small groups that has improved your communication skills?" there was an increase of $12.0 \%$ in the affirmative answer with only an almost statistically significance from the Tourism results. 


\subsubsection{Bibliography Competence}

With regards to the bibliography research question, Item C1 - "do you know how to use databases and collect a bibliography for a research paper in your specialty?"; as can be seen in Figure 3, we have found that students' lowest pre-test levels on the self-perception for this ability are from Political Science and Tourism students.

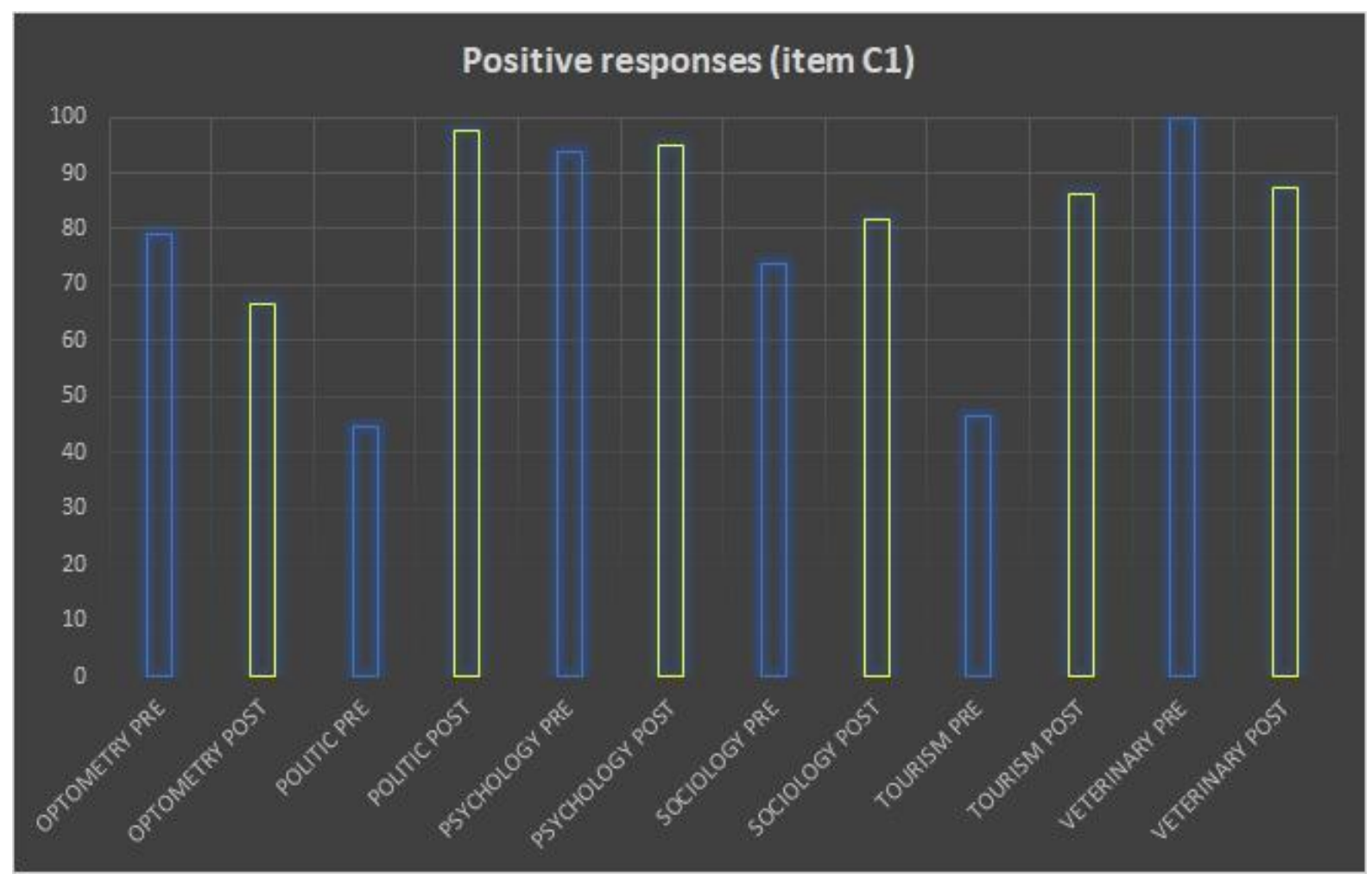

Figure 3. Percentage of positive responses on Pre and Post Tests in item C1 for all academic degrees:”Do you know how to use databases and collect a bibliography for a research paper in your specialty?"

Table 3 describes the statistical results for the significance of Item $\mathrm{C} 1$ about scientific databases knowledge. In Table 3 , statistical improvements on students' self-perceptions are observed regarding this issue from the specific fields of Political Science $(\mathrm{p}<.001)$ and Tourism $(p<.001)$, which seemed the most advanced in this area of competence, in combination with Psychology, Veterinary and Political Science students. Regarding Optometry students, a decrease was found with statistical significance $(\mathrm{p}=.016)$.

With regards to Item C2 - "Do you research for complementary information about a topic that interests you from a class or lecture (author, bibliography, etc.)?" our sample does not present significant findings in this area.

\subsubsection{Analysis and Synthesis Competence}

The Item D1 - "Do you know the steps to take in order to extract and cite information from a text?" only Political Science $(p<.001)$ presented an increase of $49.2 \%$.

Regarding Item D2 - "Do you feel capable to write a summary and present it in class?" we can conclude that our sample did not present significant findings in this area

\subsubsection{The additional Satisfaction Question}

The Item E1 "Do you feel comfortable by doing these group activities?" only showed an increase of $32.5 \%$ in Political Science $(p<.001)$. 
Table 3. Chi-Square values and significant differences between Yes and No, in Pre and Post Tests in item C1:"Do you know how to use databases and collect a bibliography for a research paper in your specialty?" for all academic degrees

\begin{tabular}{llll}
\hline Group according Degrees & Pearson Chi-Square Value & df & Signification asymptotic (bil.) \\
\hline OPTOMETRY & 5.842 & 1 & $.016^{*}$ \\
POLITICAL SCIENCE & 28.575 & 1 & $.000^{*}$ \\
PSYCHOLOGY & 0.035 & 1 & .851 \\
SOCIOLOGY & 0.536 & 1 & .464 \\
TOURISM & 13.455 & 1 & $.000^{*}$ \\
VETERINARY SCIENCE & 1.451 & 1 & .228
\end{tabular}

* Statistical significance.

\section{Discussion}

Four main hypotheses have been managed in the present study. All hypotheses were associated to each question block of competences.

The first hypothesis was that SGL influenced the self-perception of the ability to clearly express their views both verbally and in writing (papers, results, essays, reports), which are considered priority competences in undergraduate education (Chan, 2011). This first hypothesis was corroborated by the results from various degrees including Social Sciences, and specially Political Science.

Regarding this first hypothesis, it has been proposed that social interaction by small groups can increase language learning (Bygate, 1988). In addition to the results in learning motivation; cooperative learning involves oral presentations that help acquire oral expression abilities in secondary or superior education (Chou, 2011). As well as improve writing abilities (Suwantarathip \& Wichadee, 2014). This evidence about the effect in proper competences supports the benefits for self-perceptions obtained in our study.

The second hypothesis defends that Small Group Learning affects in a positive way the self-perception about the organization of information abilities from our students. We did not find any evidence that confirms or rejects this hypothesis. Presumably, this is because of the lack of any instruction on planning and negotiation skills (Brindley et al., 2009; Curtis \& Lawson, 2001), which is likely to facilitate the adequate organization of the flow of information by the group.

In relation to the self-perception of the competence related to the third hypothesis, managing the bibliography, this is improved by Small Group Learning in two academic degrees. Several studies have showed an increase of knowledge in managing bibliography in Health Sciences (Holloway et al., 2004; Kok et al., 2013; West et al., 2011): However, in our case, the boost has been on two Social Sciences: Tourism and Political Science. Students from Optometry have showed a slight decrease over their academic course on their self-perception of bibliography management. This could in turn be explained by the higher attendance of students to the post-test survey compared to the pre-test survey.

The last hypothesis considers that self-perception of reading comprehension is improved by the SGL tool. This hypothesis was not demonstrated. However, progresses related to summarizing and explaining strategies in comprehension reading was obtained decades ago (Stevens et al., 1991). Recent validation has continued to some extent from primary school research (Spörer et al., 2009), and special education (Vaughn et al., 2013; Elbaum et al., 2009). Nevertheless, studies on reading comprehension skills with undergraduates are scarce and could be due to difficulties in language adaptation found in international students (Andrade, 2006).

In two of the Social Science degrees (Political Science and Sociology), students indicated that thanks to the SGL method they have done more presentations in class, which at the same time was very well perceived as a contributing factor to their learning process.

In contrast, the participating Health Science degrees seem to have less improvement than the Social Sciences students. This fact could be due to different reasons.

In Health Sciences usual classes are carried out by experiments or conducted in lab practices. Thus, it is easier to correct and receive feedback for these specific students. Whereas in Social Sciences, this feedback must be given after the submission of written papers, or other activities which seem to be qualified as insufficient feedback from the 
instructor. This gap between possibilities to receive feedback, in addition to the more frequent work on references and scientific databases, something paramount in many Health Sciences degrees, in contrast to the Social Sciences, could explain the higher pre- level of measurements for Health Sciences students. That imbalance between the previous levels of Health and Social students in many competences has likely led to fewer competence improvements for the Health Sciences area.

Lastly, at least in half of the degrees analyzed in this inquiry, many students declared to have never received feedback for their work from their previous professors. It is important to note that the SGL has likely called their attention to this shortcoming which would have otherwise gone unnoticed. As feedback allows improvement in the performance, this is a poor practice associated to teaching with a clear need for correction.

In addition, it is important to note some limitations. First, there has not been a uniform improvement reflected on each question, and that could be a consequence of some factors such as students socialization instead of working, managing time effectively, or the assessment of the learning that occurred in the group, as others studies have shown (Gillies \& Boyle, 2010). The reduced effect of SGL on self-appraisals of competences lead us to think, according to Borůvková and Emanovský (2016), that a better approach in the future would be to move into SGL practice gradually instead of our full implementation, in order to maximize the benefits.

It is also worth mentioning that our survey implies self-report measurements and do not address competences directly. As some authors say, it is important to not use self-evaluation to judge the "accuracy" of individual's evaluation, but to help individuals analyze their work practices and performance (Stewart et al., 2000). On the other hand, studying self-perceptions should not be discarded, because it has demonstrated its value in assessing multiple and interesting elements such as meaning formation (Gilbert \& Wingrove, 2019), multifaceted perception of quality in higher education (Jungblut et al., 2015), the value of non-native teacher's authenticity in multilingual higher education settings (Yanaprasat \& Melo-Pfeiffer, 2019), or the barriers to mental health services at university (Burlaka et al., 2014).

Next approaches to the topic should include both objective and subjective methodology in order to achieve a systematic methodology to address the whole nature of competences, which encompasses knowledge, abilities and attitudes.

\section{Conclusions}

Our study has revised the usefulness of the strategy Small Group Learning (SGL) on the self-perceptions for certain competences selected. SGL has usually demonstrated an influence on better academic results, collaborative work, and self-learning.

Applying SGL in a multidisciplinary perspective, the students' perception of two main competences showed variations for more than one university degrees: oral and written expression and managing bibliography. This positive effect was true for Social Science degrees such as Political Science and for Health Science degrees such as Psychology. Although some improvements were not shown uniformly in all the academic degrees evaluated. This educational tool has a clear research in the upcoming years in a less studied area such as higher education.

Furthermore, the use of SGL allows students to be able to understand how they are ascertaining their knowledge acquisition. As well as availed us to improve the quality of learning, due to its significance, durability, transference, and generalization.

\section{Funding}

This research did not receive any specific grant from funding public agencies commercial, or non-profit sectors.

\section{References}

Andrade, M. S. (2006). International students in English-speaking universities: Adjustment factors. Journal of Research in International education, 5(2), 131-154. https://doi.org/10.1177/1475240906065589

Andreu-Andrés, M. Á., \& García-Casas, M. (2014). Evaluación del pensamiento crítico en el trabajo en grupo. Revista de Investigación Educativa, 32(1), 203-222. https://doi.org/10.6018/rie.32.1.157631

Baghcheghi, N., Koohestani, H. R., \& Rezaei, K. (2011). A comparison of the cooperative learning and traditional learning methods in theory classes on nursing students' communication skill with patients at clinical settings. Nurse education today, 31(8), 877-882. https://doi.org/10.1016/j.nedt.2011.01.006 
Bahar-Özvaris, S. E., Çetin, F. Ç., Turan, S., \& Peters, A. S. (2006). Cooperative learning: a new application of problem-based learning in mental health training. Medical teacher, 28(6), 553-557. https://doi.org/10.1080/01421590600834252

Bergsmann, E., Schultes, M. T., Winter, P., Schober, B., \& Spiel, C. (2015). Evaluation of competence-based teaching in higher education: From theory to practice. Evaluation and program planning, 52(1), 1-9. https://doi.org/10.1016/j.evalprogplan.2015.03.001

Blázquez, M., Herrarte, A., \& Llorente-Heras, R. (2018). Competences, occupational status, and earnings among European university graduates. Economics of Education Review, 62(1), 16-34. https://doi.org/10.1016/j.econedurev.2017.10.006

Bonafé, J. M. (2004). La formación del profesorado y el discurso de las competencias. Revista interuniversitaria de formación del profesorado, 18(3), 127-144.

Borůvková, R.\& Emanovský, P. (2016). Small grouplearningmethods and theireffectonlearners' relationships. Problems of Education in the 21st., 70(1), 45-58.

Brindley, J., Blaschke, L. M., \& Walti, C. (2009). Creating effective collaborative learning groups in an online environment. The International Review of Research in Open and Distributed Learning, 10(3), 1-18. https://doi.org/10.19173/irrodl.v10i3.675

Burlaka, V., Churakova, I., Aavik, O. A., \& Goldstein, D. (2014). Perceived barriers to mental health services: A mixed-method study with Ukrainian college students. European Journal of Higher education, 4(2), 167-183. https://doi.org/10.1080/21568235.2014.890524

Bygate, M. (1988). Units of oral expression and language learning in small group interaction. Applied linguistics, 9(1), 59-82. https://doi.org/10.1093/applin/9.1.59

Carriger, M. S. (2016). What is the best way to develop new managers? Problem-based learning vs. lecture-based instruction. The International Journal of Management Education, 14(2), 92-101. https://doi.org/10.1016/j.ijme.2016.02.003

Chan, V. (2011). Teaching Oral Communication in Undergraduate Sciences: Are We Doing Enough and Doing it Right? Journal of learning design, 4(3), 71-79. https://doi.org/10.5204/jld.v4i3.82

Chou, M. H. (2011). The influence of learner strategies on oral presentations: A comparison between group and individual performance. English for Specific Purposes, 30(4), 272-285. https://doi.org/10.1016/j.esp.2011.04.003

Curtis, D. D., \& Lawson, M. J. (2001). Exploring collaborative online learning. Journal of Asynchronous Learning Networks, 5(1), 21-34. https://doi.org/10.24059/olj.v5i1.1885

Deep, S., Salleh, B. M., \& Othman, H. (2019). Improving the soft skills of engineering undergraduates in Malaysia through problem-based approaches and e-learning applications. Higher Education, Skills and Work-Based Learning, 9(4), 662-676. https://doi.org/10.1108/HESWBL-07-2018-0072

Elbaum, B., Vaughn, S., Hughes, M., \& Moody, S. W. (1999). Grouping practices and reading outcomes for students with disabilities. Exceptional children, 65(3), 399-415. https://doi.org/10.1177/001440299906500309

Epstein, R. M, \& Hundert, E. M. (2002). Defining and assessing professional competence.Jama, 287(2), 226-235. https://doi.org/10.1001/jama.287.2.226

Fernandez-Rio, J., Sanz, N., Fernandez-Cando, J., \& Santos, L. (2017). Impact of a sustained cooperative learning intervention on student motivation. Physical Education and Sport Pedagogy,22(1), 89-105. https://doi.org/10.1080/17408989.2015.1123238

Garcia Aracil, A., Neira, I., \& Albert, C. (2016). Social and Cultural Capital Predictors of Adolescents' Financial Literacy: Family and School Influences. Revista de Educación, 374(1), 91-115. https://doi.org/10.4438/1988-592X-RE-2016-374-327

García Aracil, A., Neira, I., \& Lozano, J. F. (2014). The Challenges of Higher Education: Improving Graduates' Employability and Social Cohesion. Journal of the European Higher Education Area, 4(1), 15-32.

Garcia-Aracil, A., Mora, J. G., \& Vila, L. E. (2004). The rewards of human capital competences for young European higher education graduates. Tertiary Education and Management, 10(4), 287-305. https://doi.org/10.1007/s11233-004-2225-6 
Garfield, J. (1993). Teaching Statistics Using Small-Group Cooperative Learning. Journal of Statistics Education, l(1), 1. https://doi.org/10.1080/10691898.1993.11910455

Gilbert, G., \& Wingrove, D. (2019). Students' perceptions of employability following a capstone course. Higher Education, Skills and Work-Based Learning, 9(4), 650-661. https://doi.org/10.1108/HESWBL-11-2018-0121

Gillies, R. M., \& Boyle, M. (2010). Teachers' reflections on cooperative learning: Issues of implementation. Teaching and teacherEducation, 26(4), 933-940. https://doi.org/10.1016/j.tate.2009.10.034

Herrmann, K. J. (2013). The impact of cooperative learning on student engagement: Results from an intervention. Active learning in higher education, 14(3), 175-187. https://doi.org/10.1177/1469787413498035

Holloway, R., Nesbit, K., Bordley, D., \& Noyes, K. (2004). Teaching and evaluating first and second year medical students' practice of evidence-based medicine. Medical Education, 38(8), 868-878. https://doi.org/10.1111/j.1365-2929.2004.01817.x

Johnson, D. W., \& Johnson, R. T. (2014). Using technology to revolutionize cooperative learning: an opinion. Frontiers in psychology, 5(1), 1156. https://doi.org/10.3389/fpsyg.2014.01156

Johnson, D. W., Johnson, R. T., \& Holubec, E. J. (1999). El aprendizaje cooperativo en el aula. Paidós: Buenos Aires, SP.

Johnson, P. A. (1999). Problem-based, cooperative learning in the engineering classroom. Journal of professional $\begin{array}{lllll}\text { issues in engineering education and } & \text { 125(1), }\end{array}$ https://doi.org/10.1061/(ASCE)1052-3928(1999)125:1(8)

Johnson, R. T., \& Johnson D. W. (2008). Active learning: Cooperation in the classroom. The annual report of educational psychology in Japan, 47(1), 29-30. https://doi.org/10.5926/arepj1962.47.0_29

Jungblut, J., Vukasovic, M., \& Stensaker, B. (2015). Student perspectives on quality in higher education. European Journal of Higher Education, 5(2), 157-180. https://doi.org/10.1080/21568235.2014.998693

Kanthan, R., \& Mills, S. (2007). Cooperative learning in the first year of undergraduate medical education. World journal of surgical oncology, 5(1), 136. https://doi.org/10.1186/1477-7819-5-136

Kok, R., Hoving, J. L., Smits, P. B. A., Ketelaar, S. M., van Dijk, F. J., \& Verbeek, J. H. (2013). A clinically integrated post-graduate training programme in evidence-based medicine versus 'no intervention' for improving disability evaluations: A cluster randomised clinical trial. PLoS ONE, 8(1), 1-9. https://doi.org/10.1371/journal.pone.0057256

Lecce, S., Caputi, M., \& Pagnin, A. (2014). Long-term effect of theory of mind on school achievement: The role of sensitivity to criticism. European Journal of Developmental Psychology, 11(3), 305-318. https://doi.org/10.1080/17405629.2013.821944

McClelland, D. C. (1973). Testing for Competence Rather than for "Intelligence". American Psychologist, 28(1), 1-14. https://doi.org/10.1037/h0034092

Morin, E. (2011). La vía para el futuro de la humanidad, Paidós, Barcelona, SP.

Norman, C. S., Rose, A. M. \& Lehmann, C. M. (2004). Cooperative learning: Resources from the business disciplines. Journal of Accounting Education, 22(1), 1-28. https://doi.org/10.1016/j.jaccedu.2004.01.001

Saaranen, T., Vaajoki, A., Kellomäki, M., \& Hyvärinen, M. L. (2015). The simulation method in learning interpersonal communication competence-Experiences of masters' degree students of health Sciences. Nurse educationtoday, 35(2), e8-e13. https://doi.org/10.1016/j.nedt.2014.12.012

Saborit, J. A. P., Fernandez-Rio, J., Estrada, J. A. C., Mendez-Gimenez, A., \& Alonso, D. M. (2016). Teachers' attitude and perception towards cooperative learning implementation: Influence of continuing training. Teaching and teacher education, 59(1), 438-445. https://doi.org/10.1016/j.tate.2016.07.020

Schul, J. E. (2011). Revisiting an Old Friend: The Practice and Promise of Cooperative Learning for the Twenty-First Century. The Social Studies, 102(2), 88-93. https://doi.org/10.1080/00377996.2010.509370

Slavin R. E. (2014). Cooperative Learning and Academic Achievement: Why Does Groupwork Work? Anales de psicología/annals of psychology, 30(3), 785-791. https://doi.org/10.6018/analesps.30.3.201201

Slavin, R. E. (1983). When does cooperative learning increase student achievement? Psychological bulletin, 94(3), 429. https://doi.org/10.1037/0033-2909.94.3.429 
Spörer, N., Brunstein, J. C., \& Kieschke, U. L. F. (2009). Improving students' reading comprehension skills: Effects of strategy instruction and reciprocal teaching. Learning and instruction, 19(3), 272-286. https://doi.org/10.1016/j.learninstruc.2008.05.003

Springer, L., Stanne, M. E., \& Donovan, S. S. (1999). Effects of small-group learning on undergraduates in Sciences, mathematics, engineering, and technology: A meta-analysis. Review of educational research, 69(1), 21-51. https://doi.org/10.3102/00346543069001021

Steinert, Y. (2004). Student perceptions of effective small group teaching. Medical Education, 38(3), 286-293. https://doi.org/10.1046/j.1365-2923.2004.01772.x

Stevens, R. J., Slavin, R. E., \& Farnish, A. M. (1991). The effects of cooperative learning and direct instruction in reading comprehension strategies on main idea identification. Journal of Educational Psychology, 83(1), 8-16. https://doi.org/10.1037/0022-0663.83.1.8

Stewart, J., O’Halloran, C., Barton, J. R., Singleton, S. J., Harrigan, P., \& Spencer, J. (2000). Clarifying the concepts of confidence and competence to produce appropriate self-evaluation measurement scales. Medical education, 34(11), 903-909. https://doi.org/10.1046/j.1365-2923.2000.00728.x

Suwantarathip, O., \& Wichadee, S. (2014). The Effects of Collaborative Writing Activity Using Google Docs on Students' Writing Abilities. Turkish Online Journal of Educational Technology-TOJET, 13(2), 148-156.

Vaughn, S., Klingner, J. K., \& Bryant, D. P. (2001). Collaborative strategic reading as a means to enhance peer-mediated instruction for reading comprehension and content-area learning. Remedial and Special Education, 22(2), 66-74. https://doi.org/10.1177/074193250102200201

Veenman, S., van Benthum, N., Bootsma, D., van Dieren, J., \& van der Kemp, N. (2002). Cooperative learning and teacher education. Teaching and Teacher Education, 18(1), 87-103. https://doi.org/10.1016/S0742-051X(01)00052-X

West, C. P., Jaeger, T. M., \& McDonald, F. S. (2011). Extended evaluation of a longitudinal medical school evidence-based medicine curriculum. Journal of General Internal Medicine, 26(6), 611-615. https://doi.org/10.1007/s11606-011-1642-8

Yanaprasart, P., \& Melo-Pfeifer, S. (2019). Students' perceptions of authenticity of plurilingual non-native teachers in multilingual higher education settings: an exploratory and comparative case study of Geneva and Hamburg. European Journal of Higher Education, 9(3), 327-342. https://doi.org/10.1080/21568235.2019.1597749

\section{Copyrights}

Copyright for this article is retained by the author(s), with first publication rights granted to the journal.

This is an open-access article distributed under the terms and conditions of the Creative Commons Attribution license (http://creativecommons.org/licenses/by/4.0/). 